\title{
LA MONTAÑA BLANCA EN LA HISTORIOGRAFÍA CHECA ${ }^{1}$
}

por MARTIN KINDL

(Universidad Carolina)

"La tesis de la Montaña Blanca como un gran desastre nacional sin precedentes también determinó el punto de vista, desde el cual no solo se evaluaba la Montaña Blanca y los sucesos posteriores, sino también todos los sucesos anteriores, más cercanos, más distantes y lejanos."2

\begin{abstract}
Resumen
El texto se centra en el tema de la Montaña Blanca en la historiografía checa. El tema de la Montaña Blanca ha sido tratado con frecuencia en la historiografía checa y también ha sido popular entre los lectores, ya que tradicionalmente ha estado relacionado con el tema del Estado Checo. El punto de partida de mi texto es la interacción de tradiciones nacionales, datos nuevos, cambios sociales y de los historiadores. Mi intención no es cuestionar las interpretaciones que se han hecho hasta hoy, sino comprenderlas en el contexto de su época.
\end{abstract}

Palabras clave: Batalla de la Montaña Blanca; historiografía; Chequia; Guerra de los Treinta Años; nacionalismo; marxismo.

\section{The White Mountain in Czech Historiography}

\begin{abstract}
The text focuses on the topic of the Battle of the White Mountain in Czech historiography. The topic of the White Mountain has been often discussed in Czech historiography and has also been popular in public. My point of view is the interaction between national traditions, new facts, social changes and historians. My intention is not to question the interpretations that have been made until today, but to understand them in the context of time of their origin.
\end{abstract}

Keywords: Battle of the White Mountain; historiography; Czechia; Thirty Years' War; nationalism; Marxism.

1 Me gustaría agradecer la ayuda de Aneta Psotová por la traducción del texto y también los comentarios de Miguel Cabo.

2 Jaroslav PROKEŠ, "Bílá hora”, in: Jaroslav Prokeš - Miloslav Hýsek (eds.), Doba bělohorská a Albrecht z Valdštejna: sborník osmi statí [Período de la Montaña Blanca y Albrecht von Wallenstein: almanaque de ocho artículos], Praha 1934, p. 29. 
Mucho se ha escrito sobre la Batalla de la Montaña Blanca. Es uno de los temas más frecuentes ${ }^{3}$ en el entorno checo y podemos encontrarlo no solo en literatura histórica, sino también en memorias, en periodismo de opinión, en discursos y programas políticos, en libros de texto, en novelas, en poesía, en obras de teatro o en la gran pantalla. La mayor parte de las obras sobre la Montaña Blanca siempre se ha escrito alrededor de su aniversario. ${ }^{4}$

En lo que respecta a la historiografía, debemos tener en cuenta que cada historiador ha tenido que considerar el trabajo de sus predecesores. Estas referencias las encontramos no solo en las notas al pie de página, sino también al comienzo de los libros, donde, según el uso académico, debemos comentar los trabajos previos. Esa es también mi intención. Sin embargo, me gustaría evitar una mera bibliografía comentada, que no revelaría mucho sobre el problema como tal. En cambio, prefiero enfocar el problema desde un punto de vista específico (como sugiere la cita introductoria). Lo presentaré a través de un recuerdo personal.

Una vez, en la escuela primaria la profesora de historia nos contó en una lección sobre Přemysl Otakar II, sobre cómo casi pudimos haber tenido nuestro propio mar $^{5}$ y cómo los Přemyslidas podrían haber gobernado el Imperio. Pero luego llegó una triste traición y la derrota de Přemysl. Una historia similar se repitió con el asesinato de Wenceslao III y, en general, con cada pérdida territorial que experimentó el Reino de Bohemia. Y no fueron pocas, precisamente. Se podría decir -bien, hubo una profesora con esta opinión-, pero ¿qué tal los demás profesores? Esta pregunta es ciertamente correcta y puede notablemente debilitar mi exposición de la opinión general de los profesores sobre la historia checa. Sin embargo, debemos tener en cuenta cómo se forma la conciencia y la cultura histórica en cada individuo. Descubrimos que el ejemplo de un individuo a menudo puede servir de ejemplo a toda una generación, más ampliamente de una nación o de una cultura. Pero esto lo trataremos más adelante. La enseñanza de la profesora podría resumirse en estas palabras: éramos poderosos, pero ahora ya no lo somos. La cuestión de dejar de ser una potencia o malograr los intentos de (re)convertirse en una es muy fuerte y afecta a todas las naciones "civilizadas". En España, incluso toda una generación se dedicó a ella, e incluía, entre otros, al filósofo Ortega y Gasset. Esta generación tuvo que superar la decadencia española tras la pérdida de unas de las últimas colonias españolas y de los territorios dependientes. Y podríamos pasar a docenas de otras naciones, no solo en Europa. Volviendo a la Montaña Blanca, la cuestión de la batalla (de acuerdo con las numerosas pistas capturadas en las fuentes) puede verse desde este punto de vista, desde la posición de una pequeña nación que no tiene más remedio que "defenderse", una nación que anhela (volver a) ser reconocida. Desde esta posición, por lo tanto, entiendo que el tema de la Montaña Blanca resurgió no solo en 1918, sino también en el período de posguerra y en la década de 1950 y,

\footnotetext{
Ibidem, p. 29.

Esto también se aplica a esta monografía colectiva.

Aquí también podemos mencionar la añoranza del mar en países que nunca lo tuvieron: Miroslav HROCH, Hledání souvislostí: eseje z komparativních dějin Evropy [La búsqueda de las relaciones: los ensayos de la historia comparativa de Europa], Praha 2016, p. 112.
} 
a menudo, incluso más tarde. Este tema surgía con más frecuencia en los tiempos de cambio, de incertidumbre, en momentos cuando "se está partiendo el pan", como veremos pronto. ${ }^{6}$

Cada época formula sus propias preguntas a la Montaña Blanca, ya que está influenciada por circunstancias completamente diferentes (lucha antialemana, lucha de clases, etc.), pero el punto de vista principal sigue siendo el mismo: "Estamos aquí y queremos proclamar que tenemos el derecho a estar aquí y también a sobrevivir aquî". En este sentido, la Montaña Blanca realmente parece un mito. El mito de la Montaña Blanca podría aclararnos por qué nuestro Estado (o su independencia) decayó.

Mi texto será un breve compendio (y por lo tanto, también será selectivo) de la historiografía de la Montaña Blanca desde su inicio hasta nuestros días. Aun así, trato de captar el aspecto predominante de cada período del que estoy hablando. El texto se basa en las fuentes que son los propios textos historiográficos y también en la literatura de los historiadores que se dedicaron al mismo tema antes que yo.

Por el momento, tomaremos la Montaña Blanca del almacén de símbolos ${ }^{7}$ y la volveremos a mandar al escenario de la memoria histórica checa permitiendo que interprete todos sus roles.

\section{De la Montaña Blanca al período del surgimiento del nacionalismo moderno}

Aquellos que vivieron los sucesos relacionados con la Batalla de la Montaña Blanca los percibieron básicamente de dos maneras, pese a lo cual estas dos formas no eran completamente contradictorias. Del lado protestante (por ejemplo, el pensador Juan Amos Comenio o el cronista Pavel Skála de Zhoř), ${ }^{8}$ se percibió como una decadencia en la independencia y las tradiciones de las tierras checas. Sus ideológicos oponentes católicos, y ganadores de la batalla, perciben la Montaña Blanca, por supuesto, como una victoria, tanto en términos de fe como de sus ambiciones personales. Por otro lado, perciben la política posterior de los Habsburgo como un desastre. Abogaron por la tendencia de estamentos constituyendo el Estado (patriotismo estatal) ${ }^{9}$, es decir, rechazaron el absolutismo (por ejemplo, el jesuita Bohuslav Balbín o František Beckovský ${ }^{10}$ ), pero en combinación con la lealtad a la dinastía de

6 Josef PETRÁŇ, "Na téma mýtu Bílé hory”, in: Karel Beránek - Zdeňka Hledíková, Traditio et cultus: miscellanea historica Bohemica: Miloslao Vlk, archiepiscopo Pragensi ab eius collegis amicisque ad annum sexagesimum dedicata [Tradición y cultura: Miscelánea historia bohémica: Miloslao Vlk, arzobispo de Praga, por sus colegas y amigos dedicado a los sesenta], Praha 1993, p. 159.

Ibidem, p. 161.

8 De Juan Amos Comenio (1592-1670), pensador religioso y profesor, podemos mencionar su obra $\mathrm{El}$ triste [Truchlivý]. Pavel Skála de Zhoř (1583-1640?), historiador y escritor, escribió Historie církevní [Historia de la Iglesia]. Los dos se exiliaron poco después de la Batalla de la Montaña Blanca.

9 En este contexto "patriotismo estatal" se entiende como un deseo a conservar la autonomía y los derechos de los estados checos dentro de la Monarquía Habsburga. Este esfuerzo checo estuvo oprimido al final del siglo XVIII con la idea de la identidad colectiva de la nación "austriaca". Esta dirección persistía también en el siglo XIX, cuando empezaba competir con el nacionalismo moderno.

10 Bohuslav Balbín (1621-1688). Sacerdote, profesor y científico. Escribió Debate sobre la defensa de la lengua eslava, especialmente de la lengua checa [Rozprava na obranu jazyka slovanského, zvláště 
los Habsburgo. ${ }^{11}$ Esta lealtad a la dinastía durante el reinado de José II (1780-1790) suprimió ese patriotismo al estamento. ${ }^{12}$ En ese momento, también aparecen dos fenómenos que seguirán acompañando a la cultura checa: un sentimiento de injusticia y la opinión de que las tierras checas se ven obligadas a aceptar inconvenientes novedades procedentes del extranjero. ${ }^{13}$ El historiador Josef Petráň, de quien tomé prestada la información recién mencionada, también hizo una observación interesante, a saber, que en el enfoque de la revuelta bohemia se refleja (ya en este momento) "más bien la opinión social de los autores que la ignorancia de las fuentes" ${ }^{14}$ Este punto de vista debe tenerse en cuenta cuando más adelante nos encontremos con historiadores que, bajo la influencia de la historiografía empírico-crítica, pasarán por alto este aspecto del trabajo del historiador. Pero ahora volvamos a la Ilustración. Petráň añade que "a finales del siglo XVIII los ilustrados todavía entendían la historia checa sin ninguna duda como historia (nacional) eslava a consecuencia de las tradiciones más antiguas de la historiografía". ${ }^{15}$ En el Siglo de las Luces, la Montaña Blanca se convierte por primera vez en un hito histórico. Josef Dobrovsk $\hat{y}^{16}$ percibe el año 1620 como "el fin de la independencia ideológica y políticamente entendida". ${ }^{17}$ Con el historiador Zdeněk Beneš, se puede enfatizar que:

[...] desde mediados del siglo XIX hasta la década de 1930 y 1950, el estudio de la Montaña Blanca fue de hecho un estudio de la historia coetánea, ya que los sucesos desde el acceso de los Habsburgo al trono checo tuvieron repercusión constante e inmediata en los acontecimientos coetáneos, especialmente políticos. ${ }^{18}$

Y como los Habsburgo gobernaron las tierras checas hasta 1918, esta interpretación de la Montaña Blanca se puede encontrar también en los historiadores checos más famosos del siglo XIX.

La época de formación del nacionalismo moderno en el siglo XIX se separó del "pasado sociopolítico de los estamentos" que fue reemplazado por el pueblo como el portador de la idea nacional. ${ }^{19}$ A principios del siglo XIX, todavía no encontra-

pak českého]. Jan F. Beckovský (1658-1725) sacerdote, profesor e historiador, fue autor de Poselkyně starých př́běhuv českých [Mensajero de antiguas historias checas].

11 Josef PETRÁŇ, "Ke genezi novodobé koncepce českých národních dějin”, AUC - Philosophica et historica 5, Praha 1982, p. 69; Jaroslav WERSTADT, Odkazy dějin a dějepisců [Herencia de historia y los historiadores], Praha 1948, p. 143.

12 PETRÁŇ, "Ke genezi”, p. 71.

13 Idem, "Na téma mýtu", pp. 147-149.

14 Idem, "Ke genezi", p. 76.

15 Ibidem, p. 81.

16 Josef Dobrovský (1753-1829), sacerdote, filólogo, fundador de los estudios eslavos y una de las personas creativas creadoras del "Resurgimiento nacional checo".

17 Zdeněk BENEŠ, "Raný novověk v českém historiografickém výzkumu” in: Marie Koldinská (ed.), Základní problémy studia raného novověku [Los problemas principales del estudio de la edad moderna], Praha: Lidové noviny, 2013, pp. 28.

18 Ibidem, p. 31.

19 PETRÁŇ, "Na téma mýtu”, p. 150. 
ríamos el "simbolismo unificado de la Montaña Blanca". ${ }^{20}$ Desde la revolución de 1848, no obstante, ya se la señalaba como el Gólgota de la nación checa. ${ }^{21}$ El siglo XIX ya no añadió nada más al mito, y en general se puede afirmar que en ese momento "las ideas democráticas del siglo XIX están injertadas en las medidas feudales del Estado de estamentos" del siglo XVII. ${ }^{22}$

Uno de los fundadores de la concepción moderna de la historia checa fue František Palacký (1798-1876), conocido en Chequia como el Padre de la nación, cuya obra maestra, Dějiny národa českého v Čechách i na Moravě [Historia de la nación checa en Bohemia y Moravia], describe la historia checa desde la prehistoria hasta 1526, es decir, hasta el acceso de los Habsburgo al trono checo. En la obra también explicó la "filosofía nacional checa" a la que se referirán las generaciones posteriores y que tendrá una gran influencia al menos hasta los años 50 del siglo XX. ${ }^{23}$ Aunque el trabajo de Palacký ya no abarca evidentemente el tema de la Montaña Blanca, se puede encontrar en sus obras que la derrota en la Montaña Blanca se debe a "la defraudación de la nación a sí misma". ${ }^{24}$ El marco de referencia de Palacký para evaluar la revuelta bohemia (y su final) fueron los husitas, ${ }^{25}$ para él mismo el período más famoso de la historia checa. A lo largo de la época de los husitas, la nación debía unirse como un todo y así defenderse "de toda Europa". Según Palacký, la nación estaba gobernada por la Providencia y participaba en la Historia contribuyendo a la reforma de la religión: tanto en la época de los husitas como en la de la Montaña Blanca, la nación checa está a la vanguardia en este esfuerzo a nivel mundial. ${ }^{26}$ Para Palacký, el nacionalismo checo se transmite por el mensaje checo del supuesto pacifismo eslavo, la democracia y los ideales de la humanidad. ${ }^{27}$ Por lo tanto, Palacký condenó a los derrotados estamentos checos por su egoísmo, ya que por ellos pagó el pueblo (la mayor parte de la nación) al ser oprimido posteriormente por los Habsburgo. ${ }^{28}$ Aquí nace el "estereotipo negativo del papel histórico de la nobleza checa" 29 típico de la sociedad checa.

Otro nivel de interpretación de la revuelta bohemia y la Montaña Blanca fueron las obras de los historiadores Václav V. Tomek, Josef Kalousek y Antonín

20 Ibidem, p. 151.

21 Ibidem, p. 152.

22 Ibidem, p. 153.

23 Aunque la influencia fue paulatinamente descendiendo.

24 Zdeněk BENEŠ, "Bílá hora a české dějiny po čtyřiceti letech" in: František KAVKA, Bílá hora a české dějiny [La Montaña Blanca y la historia checa], Praha 2003, p. 13.

25 Josef PETRÁŇ, Staroměstská exekuce: několik stránek z dějin povstánífeudálních stavů proti Habsburkuim v letech 1618-1620 [Ejecución de la Ciudad Vieja: unas páginas de la historia de la revuelta del estado feudal contra los Habsburgo 1618-1620], Praha 1972, p. 213. Husitas: un movimiento religioso-social del período bajomedieval en Bohemia. Su nombre se originó a partir de Jan Hus (?-1415), reformador checo. Durante el período contemporáneo los husitas fueron percibidos como los primeros luchadores por la libertad democrática.

26 WERSTADT, Odkazy dějin, p. 18.

27 Ibidem, p. 21.

28 PETRÁŇ, Staroměstská exekuce, p. 215.

29 Jiří RAK, Bývali Čechové: české historické mýty a stereotypy [Los checos de pasado. Los mitos históricos y los estereotipo], Jinočany 1994, p. 131. 
Rezek en la segunda mitad del siglo XIX. Tomek fue el iniciador, cuyo trabajo los otros dos historiadores aceptaron y desarrollaron a su manera. El fundamento de esta interpretación se basa en el hecho de que condenaron claramente la revuelta bohemia y encontraron sus causas en el declive moral de la época. ${ }^{30} \mathrm{Al}$ igual que Palacký, destacaron la actividad nacional de los husitas. ${ }^{31}$ En el siglo XVII, por otro lado, los estamentos "no nacionalistas" incurrieron en anarquía bajo la influencia del luteranismo alemán. ${ }^{32}$ Los historiadores ven el punto de partida en la conexión de la nación checa con la idea del Estado austriaco. Según ellos, los Países Checos deberían permanecer dentro del imperio de los Habsburgo. Esta interpretación es nacional, pero al mismo tiempo antidemocrática. Esta fue también la razón por la cual este concepto fue fuertemente criticado en su desarrollo posterior.

Por el contrario, Antonín (Anton) Gindely (1829-1892) se hizo más respetado entre los eruditos checos con su trabajo, que debió complementar la historia de Palacký hasta el final de la Guerra de los Treinta Años. ${ }^{33}$ Desafortunadamente, en el momento en que prevalecía el tipo de nacionalismo centroeuropeo, ${ }^{34}$ tuvo la mala suerte de ser "solo medio checo". ${ }^{35}$ A pesar de este asunto que le fue reprochado, ${ }^{36}$ se convirtió en autor de una obra basada en un extenso estudio de fuentes en el extranjero a la que la mayoría de los historiadores recurrió hasta hace poco. ${ }^{37}$ Además del material de archivo recopilado e interpretado, también estableció el marco para el estudio de la historia nacional reflejando el contexto extranjero. ${ }^{38}$ Este método se convirtió en el marco general para el estudio de la revuelta bohemia incluso en la primera mitad del siglo XX y en parte quizá hasta el día de hoy. Por esta razón, presentaremos su trabajo de manera un poco más amplia que las obras de sus predecesores e indicaremos los momentos que jugaron un papel en los historiadores checos posteriores.

Gindely trató la historia principalmente en términos de política de la época y campañas militares. Como se ha mencionado anteriormente, la revuelta bohemia para él es un tema que conecta la historia checa con la historia europea..$^{39} \mathrm{Y}$ no solo

30 PETRÁŇ, Staroměstská exekuce, pp. 215-216.

31 RAK, Bývali Čechové, p. 131.

32 Josef PETRÁŇ, Staroměstská exekuce, 4 ed., Praha 2004, p. 296.

33 Sin embargo, según el público de la época, no cumplió su papel y, como veremos, lo asumió Ernest Denis en su lugar.

34 Nacionalismo basado en el origen y el idioma. Cf. Ernest GELLNER, Nations and nationalism, New York 2008.

35 PETRÁŇ, Staroměstská exekuce, p. 215.

36 Gindely carecía de una "conciencia nacional profunda" porque era un "austriaco anfibio". WERSTADT, Odkazy dějin, p. 28.

37 La obra de Gindely incluye datos de fuentes que se pueden seguir aprovechando: Josef POLIŠENSKÝ, "Období prosazení a utužení druhého nevolnictví 1620-1627)" in: František Graus (ed.), Přehled československých dějin: these. I, (Do roku 1848) [Resumen de la historia checoslovaca: vol. I (hasta 1848)], Praha 1954, p. 408. Josef JANÁČEK, “České stavovské povstání 1618-1620. (Otázky a problémy)", Folia Historica Bohemica 8, Praha 1985, p. 8.

38 PETRÁŇ, "Na téma mýtu”, p. 156; Jiří JANÁČ - Jaroslav IRA, "Komparace, relace, kontextualizace... České světové dějiny a světové dějiny Česka”, Dějiny a současnost 41, Praha 2019, pp. 13-15.

39 Antonín GINDELY, Dějiny českého povstání léta 1618. Díl 1 [Historia de la revuelta bohemia 1618. Vol I]], Praha 1870, p. 291; Idem, Dějiny českého povstání léta 1618. Díl 2 [Historia de la revuelta 
eso, según Gindely, en ese momento los problemas de las tierras checas ocupan el primer lugar en importancia para toda Europa. La nación checa experimenta así una especie de primacía simbólica sobre otras naciones. Para Gindely, las ambiciones de poder en la política, que también se reflejan en la esfera religiosa, son la causa principal de la revuelta bohemia y la posterior Guerra de los Treinta Años. ${ }^{40}$ Esto también le permite afirmar que los estamentos derivaron sus acciones rebeldes de la violación de la convención religiosa de la Carta de Majestad de Rodolfo II cuya emisión forzaron en 1609 por presión política. Por el contrario, los Habsburgo consideraron inválida la Carta de Majestad emitida en esas circunstancias y, por lo tanto, no rehuyeron violarla. ${ }^{41}$ Añade a este conflicto el esfuerzo principal de la Iglesia Católica en ese momento: la recatolización..$^{42}$ Vio al instigador principal de toda la resistencia en España y en sus aliados en la corte del emperador Matías y Fernando II. Esta "facción española" abogó por una solución a la vida y muerte en la lucha contra la revuelta bohemia. ${ }^{43}$ Los españoles no querían perder a los checos como fuente económica ni su voto a la hora de elegir al emperador. Otro tema es la condenación de los posibles aliados extranjeros de los checos: la política de Inglaterra y la "cobardía" ${ }^{44}$ del rey Jacobo I o su yerno Federico V del Palatinado ${ }^{45}$ Finalmente, no olvida el papel de las "clases populares". En su evaluación, Gindely parcialmente acepta las fuentes de información sin interpretación crítica. Esto le permite afirmar que el pueblo estaba al tanto de la traición de la revuelta bohemia ${ }^{46} \mathrm{Y}$ no solo los checos, sino también los ingleses. ${ }^{47}$ Gindely incluso otorga gran importancia a los levantamientos campesinos durante la guerra de los nobles protestantes contra el Imperio: en su opinión, si esta guerra no hubiera terminado en la Montaña Blanca, los campesinos se habrían rebelado en todo el país. ${ }^{48}$ Gindely continuó con la idea tradicional checa y comparó el ejército de los nobles sublevados en la Montaña Blanca con el ejército "nacional" husita. ${ }^{49} \mathrm{Habla}$ del egoísmo de los nobles sublevados que no permitió que se manifestara el "patriotismo entusiasta" de la mayoría de los checos. ${ }^{50}$ Ve la derrota de los sublevados en la falta de finanzas, en un mal líder, en la escasez de "conciencia nacional" y en oportunidades no aprovechadas. ${ }^{51}$ En su consecuencia, la Montaña Blanca marcó la mayor decadencia de la independencia

bohemia 1618. Vol II], Praha 1878, p. VI. Supuestamente parecidas son solamente las épocas del reinado de Carlos IV (1346-1378) y Wenceslao IV (1378-1419), gobernantes checos y reyes de los romanos.

40 Las razones económicas también desempeñaron su papel, aunque quedan en segundo plano.

${ }^{41}$ GINDELY, Dějiny českého povstání. Díl 1, p. 214.

42 Ibidem, p. 65.

43 Ibidem, p. 272.

44 Idem, Dějiny českého povstání. Díl 2, p. 36.

45 Idem, Dějiny českého povstání. Díl 4, Praha 1880, p. 331.

46 Idem, Dějiny českého povstání. Díl 1, p. 334.

47 Idem, Dějiny českého povstání. Díl 3, Praha 1878, p. 33.

48 Ibidem, p. 243.

49 Ibidem, p. 265.

50 Ibidem, p. 52

51 Ibidem, pp. 275-276. 
en la historia, ya que "se rompió la unión del monarca con sus súbditos". ${ }^{52}$ Gindely dejó un legado más a la historiografía posterior: la necesidad de seguir buscando fuentes nuevas. Este centro de historiografía del siglo XIX tendrá voz en Chequia a lo largo del siglo XX. Gindely incluso mandó una tarea a los historiadores sucesivos: es necesario procesar una gran cantidad de fuentes que se encuentra no solo en archivos extranjeros, sino también en tierras checas, especialmente en archivos aristocráticos privados. ${ }^{53}$ Como veremos más adelante, el historiador Josef Polišenký se hizo cargo de esta tarea más tarde.

Analizando la obra de Gindely, mostraremos cómo trabaja con el material histórico. Como cualquier otro historiador, aplica el siguiente procedimiento: para que el texto sea comprensible, no se puede evitar el proceso de simplificar la información del material que se ha estudiado. Esto no significa que sea necesario modificar las fuentes, sino que tiene que elegir la información, enlazarla y convertirla en una narración con sentido. ${ }^{54}$ Estos "niveles de simplificación” significan para Gindely la formación de opuestos duales: catolicismo / protestantismo, estamentalismo / absolutismo, reacción / progreso, alianza militar (Unión Protestante) / alianza militar (Liga Católica), Estado / Estado, política / economía, personaje / personaje. Y ciertamente se podría continuar. ${ }^{55}$

La labor del historiador es, por lo tanto, en cierta medida cercana a la combinatoria matemática. La combinación de todas estas contradicciones en una narración con un resultado requiere trabajo para encontrar un significado y un vínculo común. No es fácil entrelazar todos los niveles de actores individuales (ya sean personajes, grupos o intereses). Para los historiadores, la historiografía también proporciona pistas para revelar el momento en que se creó el texto.

Un contribuyente interesante a la historia de la revuelta bohemia y la problemática de la Montaña Blanca fue el historiador francés Ernest Denis (1849-1921), quien vivió en Bohemia e investigó allí la historia checa. Sin embargo, el trabajo de Denis se basó solo en la literatura checa existente, que trató de desarrollar y adaptar aún más a la "demanda" social de aquel entonces. Describió la revuelta bohemia como un desarrollo del legado husita, pero debido a la supuesta decepción moral de los estamentos, estos no pudieron lograr su objetivo y tuvieron que perder. Debido a esto, las tierras checas perdieron su independencia, renombre y se convirtieron en una provincia. ${ }^{56}$ No obstante, esta mala suerte también jugó un papel importante: los checos se salvaron de la fusión con los alemanes (es decir, de la desaparición de la independencia del Estado y la nacionalidad checas) y de la anarquía aristocrática como Polonia en aquella época.$^{57}$ Denis fue considerado el seguidor ideológico de

52 Idem, Dějiny českého povstání. Díl 4, p. 68.

53 Idem, Dějiny českého povstání. Díl 2, p. 5.

54 Para eso sirve el estilo del historiador, es decir, el estilo de escritura. En la fase final, ese determina la forma del enunciado: Roman PAZDERSKÝ, Golli̊v styl: studie k historickému myšlení Jaroslava Golla [El estilo de Goll: estudio del pensamiento histórico de Jaroslav Goll], Praha 2018.

55 Semejante PETRÁŇ, Staroměstská exekuce, p. 291.

56 Ibidem, pp. 216-217.

57 František KAVKA, Bílá hora a české dějiny [La Montaña Blanca y la historia checa], Praha 1962, p. 10. 
František Palacký por los lectores de la época y la audiencia científica ${ }^{58}$ Este hecho seguramente nos sorprenderá al fijarnos en que el francés Denis supuestamente expresó mejor la historia de la nación checa que Antonín Gindely que era checo solo por parte de uno de sus padres. Pero al mismo tiempo, este hecho también nos muestra que, incluso en el marco del nacionalismo centroeuropeo, lo importante no es la nacionalidad del escritor, sino el tono que emplea en su trabajo.

\section{Historiografía empírico-crítica e ideas de la Primera República Checoslovaca}

El siglo XIX fue también la época de la llegada de la llamada historiografía "positivista" o, más bien, empírico-crítica. ${ }^{59}$ Para las tierras checas su símbolo sigue siendo el historiador Jaroslav Goll (1846-1929), pero ciertamente podemos incluir también a Antonín Gindely. Goll y la escuela que fundó se centraron en interpretar la historia checa en estrecha relación con la historia de Europa occidental. ${ }^{60}$ Aunque esta escuela se centró principalmente en el estudio de las fuentes y la escritura de obras basadas en hechos y el desprecio hacia las filosofías nacionales, ni ella resistió al nacionalismo coetáneo ${ }^{61} \mathrm{Y}$ tampoco podía, porque este discurso (especialmente en el contexto del duelo nacional checo-alemán) fue verdaderamente omnipresente. Es por eso que Goll consideraba la Montaña Blanca un desastre. ${ }^{62}$ Por la disputa entre esta escuela y el filósofo y sociólogo Tomáš G. Masaryk ${ }^{63}$ dentro de la llamada "disputa sobre el significado de la historia checa" ${ }^{64}$ la nación continuó siendo definida por su pasado. ${ }^{65}$ Aunque los partidarios de Masaryk y Goll discutieron sobre si la filosofía (humanidad condicionada por el cristianismo protestante) era superior a la evidencia basada en hechos históricos (y la idea de la tradición nacional checa basada en ella), ${ }^{66}$ ambas partes, basándose en sus fundamentos, intentaron encontrar la idea esencial de la historia checa.

Con el establecimiento de la Primera República Checoslovaca en 1918, se creó un mito sobre la esclavitud nacional que habría durado trescientos años y comenzado con la derrota en la Montaña Blanca.$^{67}$ Según él, en 1918 le fue "devuelta" la

58 WERSTADT, Odkazy dějin, p. 48.

59 Zdeněk BENEŠ, "Narratio, noesis a čas. Poznámky k jednomu aspektu chápání dějin a historie", Přednášky z 52. běhu Letní školy slovanských studií [Los discursos de la quincuagésima segunda marcha de La Escuela de verano de los estudios eslavos], Praha 2009, p. 135.

60 PAZDERSKÝ, Golliov styl, pp. 77-78.

${ }^{61}$ PETRÁŇ, "Na téma mýtu", pp. 131 y 160.

62 Idem, Staroměstská exekuce, p. 218.

63 T. G. Masaryk (1850-1937) fue el primer presidente de la república de Checoslovaquia.

${ }^{64}$ Fue una disputa sobre la interpretación de la historia y las perspectivas del nacionalismo checo, véase: Roman PAZDERSKÝ, "Příběh sporu o smysl českých dějin”, Historický obzor I.-II., Praha 2012, pp. 30-39. Esta disputa tuvo varias fases y tuvo lugar desde finales del siglo XIX hasta la década de 1930: Josef PETRÁŇ, "Spor o smysl dějin a dějepisu", Acta Universitatis Carolinae: Philosophica et historica 5, Praha 1988, pp. 29-67.

65 PETRÁŇ, Staroměstská exekuce. p. 298.

${ }_{66}$ WERSTADT, Odkazy dějin, p. 36.

67 Jan RYCHLÍK, "Bitva na Bílé hoře a mýtus o třistaleté porobě: (transformace mýtu v dějinném vývoji)", in: Literární mystifikace, etnické mýty a jejich úloha při formování národního vědomí: sborník př́spěvků z mezinárodní konference konané ve dnech 20.-21. 10. 2001 [La mistificación literaria, mitos étnicos y su papel en la formación de la conciencia nacional: almanaque de los artículos de la 
independencia a la nación checa. Sin embargo, este mito ya pasaba por alto el hecho de que no solo la nación checa formaba parte de Checoslovaquia, sino que también vivían en el país alemanes, eslovacos, gitanos, húngaros, judíos, polacos y rutenos. Por lo tanto, este mito no era adecuado para consolidar tal Estado. ${ }^{68}$ Después de todo, su "miopía", junto con otros problemas, se hicieron evidentes en 1938, cuando la Primera República desapareció.

Uno de los historiadores más importantes de la Checoslovaquia de entreguerras fue Josef Pekař ${ }^{69}$ Pekař continuó con el trabajo de František Palacký en la rama alternativa de la historiografía de V. V. Tomek y creó a partir de ello una nueva síntesis que correspondía a las condiciones sociales de su época. Desafortunadamente, ni él se dio cuenta de que era anacrónica, como mencionamos en el párrafo anterior. Para Pekař, la Montaña Blanca fue un "desastre sin medida y sin límites" 70 en el sentido de las consecuencias que tuvo para la independencia del Estado checo. Sin embargo, ve las causas del desastre principalmente en los protagonistas de la revuelta bohemia. En la lucha entre los estamentos y los Habsburgo, identificó un duelo entre dos unidades culturales: románico-católica y germano-protestante. Fue precisamente esta influencia germánica la que suprimió la influencia románico-católica, en la que la nación checa debía tener una tradición ya desde la Edad Media, y causó la derrota y deshonra de la nación checa. ${ }^{71}$ Pekař creó la única monografía sobre la Montaña Blanca ${ }^{72}$ (para la siguiente se esperará hasta la década de 1960). ${ }^{73}$ Una corriente de autores católicos también continuó en la interpretación de Pekař. Nos encontraremos con uno de ellos, Bohdan Chudoba, más adelante.

El historiador Jarolav Prokeš (1895-1951) también comentó la Montaña Blanca. En el estudio mencionado anteriormente, describe la derrota en la Montaña Blanca como un "desastre nacional" 74 . Se habría llevado a cabo por la opresión de la nación por dos bandos extranjeros: católicos agresivos y protestantes alemanes que con su duelo rompieron el conciliador régimen religioso-político establecido en tierras checas por la Carta de Majestad de Rodolfo II.

Hay que mencionar que, en el marco de la interpretación nacionalista checa, la defensa de la revuelta bohemia y la maldición de la derrota en la Montaña Blanca alcanzó, incluso, una dimensión religiosa. Esto no fue solo un rasgo de la historiografía de la Primera República, sino que estas tendencias ya habían aparecido antes y ahora culminaron. El historiador Jaroslav Werstadt (1888-1970) atribuyó

conferencia internacional de 20 y 21 de octubre de 2001]. Uherské Hradiště 2001, p. 89. Uno de los ejemplos es la ya mencionada obra de J. Werstadt.

68 Ibidem, p. 89.

69 J. Pekař (1870-1937) fue un importante personaje en la cultura checa, rector de la Universidad Carolina, nombrado más tarde candidato a la presidencia.

70 Josef PEKAǨ, Bílá hora: její př́ičiny i následky [La Montaña Blanca: sus causas y consecuencias], Praha 1921, p. 159.

71 KAVKA, Bílá hora, p. 12.

72 BENEŠ, "Bílá hora", p. 7.

73 KAVKA, Bílá hora, p. 13.

74 PROKEŠ, "Bílá hora”, p. 59. 
el papel del arcángel bíblico, "un ángel guardián con una espada de fuego", ${ }^{75}$ a los historiadores nacionales, y también añadió el tema de la Montaña Blanca al "altar del amplio culto de lo nacional". ${ }^{76}$ Su compañero, historiador y diplomático Kamil Krofta (1876-1945), habló, por ejemplo, del trabajo de František Palacký como del “evangelio de la sabiduría nacional" ${ }^{77}$ En este contexto, la fundación de Checoslovaquia se percibió como la "resurrección" de la nación y del Estado.

En su obra, Jaroslav Werstadt también confirmó la idea repetida anteriormente de que "la derrota en la Montaña Blanca privó a la nación checa de la posibilidad de intervenir de manera independiente en la historia mundial durante mucho tiempo". ${ }^{78}$ Este es un motivo que ya pudimos ver en Palacký o Gindely y lo notaremos aún durante el siglo XX. La potencia del poder del Estado checo en la Edad Media y en parte también aún en la temprana Edad Moderna se pone en contraste con la evolución posterior a la Montaña Blanca. ${ }^{79}$

\section{El fin de la Primera República Checoslovaca y la historiografía después de la Segunda Guerra Mundial}

La Montaña Blanca formó parte de la memoria histórica incluso en el siglo XX. La memoria como "una presentación del pasado en la vida presente [...] está sujeta a actualizaciones constantes". ${ }^{80}$ Un nuevo ímpetu para tal actualización llega en 1938. Con base en los acuerdos de Múnich, Checoslovaquia pierde las partes históricas de su territorio y en menos de un año se desintegra por completo. Es cuando llegó la hora de un nuevo papel para la Montaña Blanca. La derrotada nación checa busca en los libros de historia pasajes que correspondan a la situación de la época. Podemos incluir la idea humanista checa de Palacký y Masaryk o la idea nacional de Pekař y su resistencia a lo alemán. Por lo tanto, después de haber terminado la Segunda Guerra Mundial, es posible afirmar que "la Montaña Blanca sigue siendo una tarea y un problema vivos hoy y en el futuro". ${ }^{81}$ El mismo principio fue seguido en ese momento por el historiador católico Bohdan Chudoba (1909-1982) quien emigró en 1948 (después de haber comenzado la dictadura socialista) y finalmente se estableció en Madrid. La nación y la "raza" (eslavismo) es para Chudoba una especie de esencia, que es un regalo de Dios. ${ }^{82}$ Para Chudoba, la cumbre estatal fue el Imperio Romano medieval, ${ }^{83}$ que era un símbolo de la unidad cristiana, pero solo hasta que los alemanes empezaron a expandirse a costa de los eslavos. ${ }^{84}$ Según Chudoba, la unidad en la fe también presupone la unidad en la nación. De aquí ya intuimos

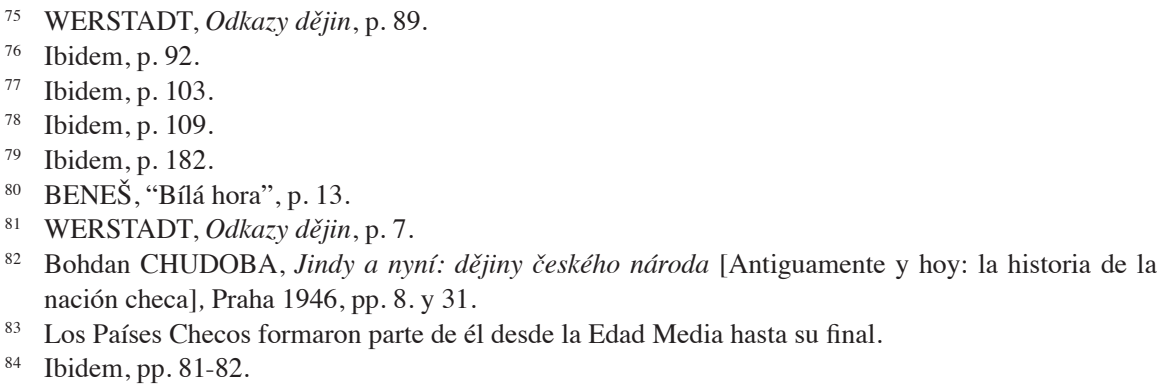


que Chudoba fue partidario de la "recatolización”. Por esta razón, también condena la influencia protestante en el marco de la revuelta bohemia por ser anárquica y en contra de la nación. ${ }^{85}$ Ve en la influencia protestante la instigadora de la revuelta y del triste destino de las tierras checas tras la derrota en la Montaña Blanca. Sin embargo, de igual manera, evalúa negativamente también los esfuerzos absolutistas de los gobernantes de los Habsburgo. ${ }^{86}$ Aun así, la "solución de los Habsburgo" le parece a Chudoba menos peligrosa. Chudoba sostiene la teoría de las diferencias culturales que notamos en la obra de Josef Pekař. Según Chudoba, las tierras checas se encuentran en la frontera de estos mundos culturales y en ellas se debe decidir hacia dónde se dirigirán no solo los checos sino también Europa ${ }^{87}$ A pesar de los puntos débiles antes mencionados en la política de los Habsburgo, considera que la derrota de la revuelta es una "victoria de la Montaña Blanca". ${ }^{88}$ Por el contrario, en los esfuerzos de los estamentos protestantes alemanes, que participaron en la revuelta bohemia, incluso ve una señal del protectorado nazi de Bohemia y Moravia. ${ }^{89}$

Chudoba ya había tratado directamente el tema de la Montaña Blanca en el libro Španělé na Bílé hoře [Los españoles en la Montaña Blanca], que más tarde también se publicó en inglés. Chuboba sigue a Gindely cuando afirma que los sucesos checos de la época "se convierten en acontecimientos a nivel mundial" ${ }^{90}$ A nivel histórico-filosófico, sin embargo, el libro contiene solo lo que mencionamos en el párrafo anterior. Culpa al protestantismo y a los estamentos de la derrota de la nación checa. Aunque perjudicó la condición del Estado checo, el absolutismo de los Habsburgo como el único régimen mantuvo la "responsabilidad política" y trajo el orden..$^{91}$ Para los Habsburgo de España, no obstante, a finales del siglo XVI el espíritu del absolutismo prevaleció sobre el espíritu religioso. ${ }^{92}$ Consideraron las tierras checas una "parte necesaria del imperio", a sus parientes austriacos. La Batalla de la Montaña Blanca fue, sobre todo, "un gran éxito para las ideas políticas de España y el imperialismo español en Europa Central". ${ }^{94}$ El concepto de Chudoba no fue seguido, es más, fue condenado por los historiadores marxistas. ${ }^{95}$

85 Ibidem, p. 110.

86 Ibidem, p. 167.

87 Ibidem, p. 217.

88 Ibidem, p. 251.

89 Ibidem, p. 263. El territorio de las tierras checas que quedó bajo la administración alemana en los años 1939-1945.

90 Bohdan CHUDOBA, Španělé na Bílé hoře: tři kapitoly z evropských politických dějin [Los Españoles en la Montaña Blanca: tres capítulos de la historia política de Europa], Praha 1945, p. 9.

91 Ibidem, p. 44.

92 Ibidem, p. 183.

93 Ibidem, p. 159.

94 Ibidem, p. 261

95 Bohumil BAĎURA - Josef POLIŠENSKÝ, "Falešný obraz Bílé hory", Československý časopis historický 3, Praha 1955, pp. 674-679. A los autores no les gustó, ante todo, su catolicismo fundamentalista y la modificación de la información de los documentos de archivo. En la misma línea: Josef POLIŠENSKÝ, Historik v měnícím se světě [Historiador en el mundo cambiante], Praha 2001, p. 134. Por otro lado, Pavel Marek en la actualidad aprecia en el trabajo de Chudoba que "sigue siendo un 
El tema de la Montaña Blanca se transformó fácilmente en un esquema marxista de desarrollo histórico, que se creó después de 1945, especialmente después de $1948 .^{96}$ En su marco, la revuelta bohemia se ve como un progreso, mientras que el absolutismo es contemplado como una regresión..$^{97}$ La Montaña Blanca y su concepción estaban ideológicamente limitadas bajo la dictadura socialista. Por ejemplo, el Comité Central del Partido Comunista decidió hasta la periodización de la historia checa. ${ }^{98}$ El tema de la Montaña Blanca se refería a las luchas de clases, y las luchas de clases a su vez influyeron en la reorganización de las tradiciones culturales checas que formaron parte de la historiografía marxista. La reorganización de las tradiciones está relacionada principalmente con el período del estalinismo. En ese momento, la historia no se estudió como un conjunto de problemas, sino como sucesos demarcados por las fronteras checas. Además, la historiografía estalinista no trajo ninguna monografía sobre la Montaña Blanca. Pero desde la segunda mitad de la década de 1950 y aún más en la década de 1960, empiezan a desaparecer estos objetivos. La historiografía sigue en gran medida las corrientes previamente prohibidas, como la psicología o la sociología, y al mismo tiempo aprovecha el revisionismo filosófico marxista. Asimismo, trata de devolver la historia checa al contexto internacional, como veremos, por ejemplo, en la obra de Josef Polišenský o František Kavka. ${ }^{99}$

Josef Polišenský (1915-2001) escribió la mayor parte de los trabajos sobre la temprana Edad Moderna en tierras checas desde la perspectiva de la metodología marxista. Polišenský une el marxismo con la búsqueda de nuevas fuentes de archivo. ${ }^{100}$ En la investigación de archivo, sigue conscientemente los esfuerzos de Antonín Gindely e intenta continuar donde Gindely terminó (pero bajo la influencia de la metodología marxista). Convirtió la información nueva encontrada en el archivo en fuente para su tesis (que también parcialmente tuvo su origen en Gindely ${ }^{101}$ ) sobre la lucha entre dos centros socioeconómicos en Europa: el feudalismo español y el

trabajo clave para aprender sobre las relaciones entre las dos ramas de la casa de los Habsburgo": Pavel MAREK, "Španělská strana na císařském dvoře? K problematice jednoho pojmu z politických dějin”, Český časopis historický 113/4, Praha 2015, p. 967.

96 BENEŠ, "Raný novověk", p. 29.

97 Ibidem, p. 38.

98 Véase el libro František GRAUS (ed.), Přehled československých dějin: these. I, (Do roku 1848) [Resumen de la historia checoslovaca: vol. I (hasta 1848)], Praha 1954.

99 BENEŠ, "Raný novověk", p. 38.

100 El resultado fueron las obras Josef POLIŠENSKÝ et al., "Otázky studia obecných dějin I, Prameny k obecným dějinám v českých archivech a knihovnách", Acta Universitatis Carolinae. Historica 4, Praha 1957; Josef POLIŠENSKÝ et al., Documenta Bohemica bellum tricennale illustrantia. Tomus I, Der Krieg und die Gesellschaft in Europa 1618-1648, Praha 1971. Sin embargo, las nuevas fuentes se convirtieron en su objetivo como una solución automática al problema histórico y no prestó mucha atención al poder interpretativo de estas pruebas: Robert J. W. EVANS. "A Czech Historian in troubled Times: J. V Polišenský” in: Tomoko Asomura (ed.), Ad honorem Josef Polišenský (1915-2001) [En homenaje a Josef Polišenský], Olomouc 2007, p. 96.

101 Josef POLIŠENSKÝ, "Současný stav bádání o Bílé hoře”, Časopis Matice moravské 70, Brno 1951, p. 19. 
absolutismo contra el capitalismo temprano de los Países Bajos. ${ }^{102}$ Polišenský se basó en la tesis marxista sobre la crisis del feudalismo en el siglo XVII. Es interesante el camino de Polišenský al tema de la temprana Edad Moderna, y nuevamente está relacionado con la forma en que el legado de la Montaña Blanca cambia de acuerdo con las condiciones de la época. Como estudiante, Polišenský fue testigo de la Guerra Civil española y de la coetánea crisis de Múnich. Estaba convencido de que el período anterior a la Montaña Blanca era similar a la década de 1930 y, por lo tanto, que esa similitud nos permitió "comprender mejor" este período. ${ }^{103}$ Estos hechos lo llevaron a estudiar la influencia española "protonacista" 104 en las tierras checas y la política "traidora" de Inglaterra anterior a la Montaña Blanca, "terminando con la debacle y la traición al bando checo-palatino en Ulm, Múnich del siglo XVII". ${ }^{105}$ En 1949, Polišenský calificó la política de Inglaterra hacia España como "la política de apaciguamiento". ${ }^{106}$ Polišenský une las ideas marxistas de progreso con la idea humanista-reformista-progresista de los checos, que ya fue apoyada por Palacký o Masaryk: "La evolución checa [...] fue una lucha por el legado de la Bohemia husita". ${ }^{107}$ Esto significa luchar por la tolerancia religiosa, las libertades sociales y económicas y la independencia del Estado. ${ }^{108}$ Polišenský también estuvo muy influenciado por la historia genética del siglo XIX, la búsqueda de "causas clave”. Por lo tanto, estaba decepcionado después de una investigación dedicada a los contactos políticos de la revuelta bohemia con Inglaterra. No encontró un sincero defensor de la revuelta en Inglaterra. Entonces empezó a estudiar la actitud de los Países Bajos. Sin embargo, va más allá en su metodología. Polišenský ya no trata el tema solo basándose en contactos políticos, sino en un estudio comparativo ${ }^{109}$ de las estructuras de ambas sociedades, es decir, en lo que estas sociedades tenían en común. A diferencia de los feudales países checos, los Países Bajos eran un país de "nuevo

102 Miroslav HROCH - Josef PETRÁŇ, 17. století - krize feudální společnosti? [E1 Siglo XVII - ¿la crisis de la sociedad feudal?], Praha 1976, pp. 80-83. La hipótesis basada en el conflicto entre la España feudal y los Países Bajos capitalistas la propuso el historiador soviético O. L. Vajnštejn. Sin embargo, Polišenský luego recurrió a la opinión más crítica de B. F. Poršněv. Los autores de esta publicación no están de acuerdo con el conflicto anteriormente mencionado y lo clasifican como un conflicto dentro de la clase feudal.

103 Ibidem, p. 261

104 POLIŠENSKÝ, Historik, pp. 10, 58, 94.

105 Ibidem, pp. 94-95.

106 Idem, Anglie a Bílá hora, Praha 1949, p. 16.

107 Idem, Historik, p. 193.

108 Idem, Tricetiletá válka a evropské krize 17. století [La Guerra de los Treinta Años y la crisis europea del siglo XVII], Praha 1970, p. 113.

109 Miroslav HROCH, "Josef Polišenský a tradice studia obecných dějin na univerzitě Karlově”, in: Tomoko Asomura (ed.), Ad honorem Josef Polišenský (1915-2001), Olomouc 2007, p. 175. Hroch menciona discusiones entre la Facultad de Filosofía de la Universidad Carolina y la Academia de Ciencias en la década de 1960 sobre la elección entre abogar por la historia general desde el "punto de vista checo" o entenderla "de alguna manera global con un enfoque en la interpretación de los procesos básicos de desarrollo y las leyes". En la obra de Polišenský no se trataba solo de "las relaciones" con respecto a la Montaña Blanca, sino de un "análisis comparativo de ambas sociedades". Miroslav HROCH, "Prof. PhDr. Josef Polišenský, DrSc. 16. 12.1915-11. 1. 2001”, in: Český časopis historický 99/2, Praha 2001, p. 409. 
tipo", encontrándose entre el feudalismo y el capitalismo. ${ }^{110}$ Con todo, los países checos, aunque feudales, se encuentran, según Polišenský, entre los miembros de la vanguardia social europea ${ }^{111}$ como los "nuevos Países Bajos". ${ }^{112}$ Los Países Bajos entraban en contacto con los países checos principalmente a través del peligro español. ${ }^{113} \mathrm{Y}$ también descubrió que la opinión pública neerlandesa estaba a favor ${ }^{114}$ de la resistencia en los países checos y la apoyaba incluso después de la retirada de Inglaterra. ${ }^{115}$ Pese a eso, los Países Bajos e Inglaterra apoyaron a los checos solo en términos de sus propios intereses económicos y políticos. ${ }^{116}$ Los abandonados estamentos checos no ofrecían perspectivas económicas ni sociales a los burgueses y los campesinos y, por lo tanto, perdieron.$^{117}$ Hay que mencionar que las obras de Polišenský se deslizan hacia el moralismo tradicional de la historiografía checa: culpa a los aliados de alevosía, incompetencia, etc. A esa opinión contribuye también la ocasional lectura de mensajes diplomáticos ${ }^{118}$ Es interesante que el libro fue publicado por segunda vez en 1991 y fue descrito por uno de los reseñadores como "parte del fondo de las mejores obras de la historiografía checa". ${ }^{119}$ Sin embargo, esta reseña se refería más bien a la edición de la obra y a las fuentes usadas en ella y no tanto a la evaluación de las circunstancias de la época de la revuelta bohemia por parte de Polišenský.

La segunda monografía que la historiografía checa registró durante el siglo XX fue la obra del historiador František Kavka (1920-2005) Bílá hora a české dějiny [La Montaña Blanca y la historia checa] ${ }^{120} \mathrm{Al}$ principio hay que señalar que este libro estaba destinado a un amplio público, por lo cual se basa en obras literarias y tiene muchas conclusiones en común con los trabajos anteriormente mencionados de Polišenský. En cada caso, es un libro enfocado exclusivamente en la Montaña Blanca y sus consecuencias. La parte principal del libro está dedicada a las tierras checas, su política, sociedad y economía. Debido al momento de su publicación, es (además de las obras de Polišenský) un libro que ya no se basa en el reflejo vulgar estalinista de la base y la superestructura, sino que trata de captar su conexión como un proceso mutuo. ${ }^{121}$ Aun así, el libro con la repetición de la perspectiva marxista no difiere de Polišenský: la Guerra de los Treinta Años como un duelo entre el centro regresivo español y el centro progresivo neerlandés, la importancia económica y cultural del Estado checo dentro del imperio de los Habsburgo, la influencia de la

\footnotetext{
110 Josef POLIŠENSKÝ, Nizozemská politika a Bílá hora, Praha 1958, p. 58.

111 Přehled československých dějin: these. I. p. 394

112 POLIŠENSKÝ, Třicetiletá válka, p. 264.

113 Idem, Nizozemská politika, p. 69.

114 Ibidem, p. 163.

115 Ibidem, p. 245.

116 Ibidem, p. 307.

117 Ibidem, p. 288.

118 Ibidem, p. 219.

119 Zdeněk HOJDA, "Tragic Triangle. The Netherlands, Spain and Bohemia 1617-1621 [El triángulo trágico. República Neerlandesa, España y Bohemia 1617-1621]”, Dějiny a současnost 4, Praha 1993, p. 64.

120 KAVKA, Bílá hora.

121 BENEŠ, Bílá hora, p. 11.
} 
crisis y de la incertidumbre económica en las causas del conflicto, el papel provocador de la "facción española", la no participación del pueblo en la revuelta bohemia debido al egoísmo de clase por parte de la aristocracia, la actualización de los acuerdos de Múnich, la aristocracia extranjera perjudicando a la nación checa, etc. Cabe destacar que este libro también se publicó por segunda vez en 2003 en reedición, es decir, sin cambios. Según el editor, el motivo para la publicación fue el papel del libro en la historia de la historiografía checa y, al mismo tiempo, es un homenaje al autor. ${ }^{122}$ El propio autor en epílogo defiende su nueva edición afirmando que aún no se ha publicado ninguna obra mejor. ${ }^{123}$

Durante la década de 1960, hubo una fuerte reflexión metodológica sobre la historiografía y también sobre las tradiciones nacionales checas. Historiadores como Josef Petráň (1930-2017) y František Graus (1921.1989) desempeñaron un papel importante. Probablemente la publicación filosófica más importante de este período $^{124}$, Dialektika konkrétního [La dialéctica de lo concreto] de Karel Kosík (1926-2003), se ha convertido en el principal marco de referencia para el texto ${ }^{125}$ de Josef Petráň que trata los cambios mencionados anteriormente. La importancia de este texto también se evidencia por el hecho de que entre los reseñadores se encuentran los personajes más importantes de la historiografía checoslovaca de aquel entonces. ${ }^{126} \mathrm{Si}$ exponemos brevemente sus tesis principales, debemos mencionar la reflexión de que la historiografía aparece siempre e inevitablemente como un esquema ${ }^{127}$ que también se aplica a los conceptos históricos. Los temas de investigación y su procesamiento están determinados por la necesidad social y su visión del futuro. ${ }^{128}$ Siguiendo a Kosík, el autor se acerca a la llamada persona concreta y al papel de la dialéctica. Por lo tanto, puede mostrar que es más productivo entender la historia dentro del marco de las mentalidades de la época que percibirla a través de opiniones de clase firmemente separadas. ${ }^{129}$ En un texto posterior ${ }^{130}$ Petráň evaluó el aferramiento de los checos al símbolo de la Montaña Blanca al decir que la predominante búsqueda de los propios valores en la historia es el consuelo de una nación a la defensiva y envuelta en xenofobia. ${ }^{131}$ En tercer lugar, mencionamos otra obra de Petráň que vale la pena recordar. En su interesante obra Staroměstská exekuce [Ejecución en la Plaza de la Ciudad Vieja], se centra no solo en la ejecución de los

22 Ibidem, p. 5.

123 KAVKA, Bílá hora (2003), s. 20.

124 Se ha traducido a varios idiomas globales, incluido el japonés.

125 Josef PETRÁŇ, "Pozdně feudální lidová hnutî”, in: Z českých dějin: sborník prací in memoriam Prof.Dr. Václava Husy [De la historia checa: almanaque de los artículos in memoriam al Prof. Dr. Václav Husa], Praha 1966, p. 115. Personalmente, lo considero uno de los textos más inspiradores de este período.

126 František Graus, Josef Kočí, Arnošt Klíma y Rostislav Nový.

127 Ibidem, p. 114.

128 Ibidem, p. 115.

129 Ibidem, p. 120n.

130 Josef PETRÁŇ, "Lid a národ v pobělohorském labyrintu”, in: František Graus (ed.), Naše živá i mrtvá minulost: 8 esejí o českých dějinách [Nuestro vivo y muerto pasado: 8 ensayos sobre la historia checa], Praha 1968.

131 Ibidem, p. 89. 
rebeldes, sino también en la historia de la revuelta bohemia en su totalidad y, por supuesto, también en la Batalla de la Montaña Blanca. El libro ha sido publicado varias veces, es decir, en varias ediciones editadas. Petráň era muy consciente de lo rápido que se hacen viejos los libros, sin importar cuán objetivas sean las fuentes de información desde las que los redactamos. En última instancia, depende ante todo del específico procesamiento estilístico de la materia. El libro de Petráň está dedicado a una amplia audiencia. Intenta reemplazar algunos términos no reflejados hasta entonces, como "el pueblo". Sin embargo, en todas las ediciones del libro, repite la misma evaluación de la política de los Habsburgo españoles en Europa Central, ya que la "facción española" sigue siendo un grupo de presión y provocación: ${ }^{132}$ "En la lucha por el poder, estaban en juego, por un lado, las libertades políticas e ideológicas de los estamentos y, por otro lado, todo el poder de la rama austriaca y la corona del Sacro Imperio Romano Germánico en la cabeza de los Habsburgo. La política europea de la segunda y más fuerte rama de los Habsburgo, los Habsburgo españoles, probablemente no sobreviviría tal pérdida". ${ }^{133}$ No obstante, este libro de Petráň no es solo una historia político-militar complementada por un contexto económico, como era común durante la historiografía marxista. Las incursiones interdisciplinarias al material histórico son completamente innovadoras. Se trata, por ejemplo, de una entrevista con un médico sobre las consecuencias de la caída de los gobernadores defenestrados o la entrada del autor en la búsqueda del cráneo de uno de los rebeldes ejecutados en forma de reportaje. Le acompaña un antropólogo que inspecciona el cráneo en el sitio.

El historiador Josef Janáček (1925-1994) también se unió a las críticas de algunos de los fenómenos asumidos por Petráñ. Se trata, sobre todo, de las opiniones ingenuas de los panfletos y propaganda de la temprana Edad Moderna, que son aceptadas por la nueva historiografía, "suponiendo sin razón el carácter vinculante de los principios éticos idealistas para los rebeldes". ${ }^{134}$ Asimismo, critica la existencia de una "constelación sociopolítica de ambos bloques" (español contra neerlandés) como demasiado esquemática. ${ }^{135}$ Janáček también critica la visión moderna de la revuelta bohemia como una "guerra de liberación nacional". " ${ }^{136}$ Aun así, para él también la Montaña Blanca y sus consecuencias supusieron un "desastre". ${ }^{137}$

\section{De la Montaña Blanca en la era neoliberal}

La caída del régimen comunista se manifestó en la historiografía checa principalmente por medio del anticomunismo y abandono del marxismo. Los historiadores de la década de 1990 con gusto apuntaban que la era de las "ideologías políticas" en la ciencia estaba llegando a su final y que por fin se podría investigar libremente. ${ }^{138}$

\footnotetext{
132 PETRÁŇ, Staroměstská exekuce, pp. 84-85.

133 Ibidem, p. 239.

134 JANÁČEK, "České stavovské”, p. 20

135 Ibidem, p. 22.

${ }^{136}$ Ibidem, p. 26.

137 Ibidem, p. 32.

138 Jaroslav PÁNEK - Robert J. W. EVANS, “České dějiny nabývají smyslu ve středoevropských souvislostech”, Dějiny a současnost 14/2, Praha 1992, pp. 49-51.
} 
El marxismo como tal fue abandonado en las ciencias históricas checas. No obstante, con esta aparente apoliticidad, algunos historiadores se han cerrado el paso a una percepción del trabajo de sus predecesores y también del suyo propio en su complejidad. En la temprana Edad Moderna, por supuesto, la investigación también se realizó bajo la influencia de teorías nuevas. Como parte de la investigación sobre la Montaña Blanca, se publicaban repetidamente las obras de Petráň, Polišenský y Kavka. Los ya mencionados textos de revistas redactados por Petráň o Beneš también son de alta calidad. La última monografía sobre la Montaña Blanca no se publicó hasta 2003 como parte de una edición de divulgación científica sobre la historia checa. Su autor es Jan Pavel Kučera. ${ }^{139}$ Su objetivo es desmitificar la historia de la Montaña Blanca tal como se ha presentado hasta hoy. Pero la forma en que el autor intenta hacerlo es crear una nueva historia realmente verdadera. El trabajo del autor se basa únicamente en la literatura, la cual al mismo tiempo critica irónicamente y presenta sus conclusiones "poniendo las cosas en su sitio". Esto también se ha convertido en el punto débil de la obra. No aporta nueva información de las fuentes, no se dedica a la metodología de los historiadores ni a los conceptos históricos. Desde la posición de un juez "objetivo", trata de criticar principalmente a los representantes de la historia aún preferida, es decir, el bando de los rebeldes.

Una de las contribuciones interesantes más recientes es el texto del historiador Pavel Marek sobre el término "facción española". ${ }^{140}$ Marek quiere renunciar al significado de este término, que hasta ahora tenía en la historiografía checa: "un poderoso grupo de católicos fervorosos que rodean y apoyan al enviado español en la corte imperial" ${ }^{141}$ o "el ala radical del bando católico en la corte imperial". ${ }^{142}$ Según Marek, se trataba más bien de una "red de contactos [...] compuesta por varios grupos de poder" ${ }^{143}$ Por lo tanto, no debía tratarse de un grupo homogéneo. La "facción española" no "reunía a personas que bajo todas las circunstancias apoyaban al enviado español y obedecían sumisamente las instrucciones de Madrid", sino quienes promovieron la unidad de la política de los Habsburgo. ${ }^{144}$ Aquí es notable como se cambiaba la percepción del término checo tradicional la "facción española". Especialmente que la facción española ya no es descrita como un enemigo del espacio checo. Otro argumento que soporta el cambio de la percepción de la batalla de la Montaña Blanca es la traducción del libro de Olivier Chaline en 2013, a la que la audiencia científica en la República Checa respondió positivamente. ${ }^{145}$

En mi opinión, después de 1989 la problemática de la batalla de la Montaña Blanca ya no es interés central entre los historiadores y la audiencia no científica como antes de 1989. Esta problemática del mito sigue viva en los círculos no críticos, radicales y nacionalistas conectados con la política contemporánea (por

139 Jan Pavel KUČERA, 8. 11. 1620 - Bílá hora: o potracení starobylé slávy české [8 de noviembre de 1620 - La Montaña Blanca: sobre la pérdida de la fama checa antigua], Praha 2003.

140 MAREK, “Španělská strana”, pp. 965-988.

141 Ibidem, p. 969.

142 Ibidem, p. 967.

143 Ibidem, p. 982.

144 Ibidem, pp. 984-985.

${ }^{145}$ Por ejemplo: Ivana ČORNEJOVÁ, "Recenze”, Marginalia histórica 2/2, Praha 2013, pp. 145-151. 
ejemplo, algunos representantes de la iglesia católica y del partido comunista). En 2020, en el año de "los destruidos monumentos", fue restaurada en Praga, con la ayuda del cardenal de la ciudad, un símbolo de la opresión después 1620, la Columna Mariana en la plaza de la Ciudad Vieja. Con exageración podemos decir, que con esto se decidieron las últimas palabras a la batalla de la Montaña Blanca: una interpretación reaccionaria sin el interés del público que celebró esta victoria.

\section{Conclusiones}

He elegido presentar el tema cronológicamente para entender mejor la evolución de la percepción de la batalla de la Montaña Blanca en la historiografía. También, el caso de la historiografía checa podría servir como un ejemplo representativo para otros países de Europa Central, porque la evolución histórica e ideológica fue similar. Pero este tipo de estudio comparativo no era el objeto del artículo. Mi objetivo era analizar el tema de la Montaña Blanca en términos de la interacción de las tradiciones nacionales, datos nuevos, cambios sociales y los historiadores. Me aproximé al texto con la comprensión previa de lo trágico que fue este suceso para las tierras checas, tal como se describe en los trabajos de los historiadores y como se enseñaba en la escuela, en mi infancia. He fijado en los cambios de la interpretación y su aplicación a varias situaciones nuevas. En este sentido, también desempeñaron el papel de un mito nacional. Seguí el enfoque del historiador Josef Petráň sobre cómo abordar tal mito: "El objetivo no es cuestionar el mito poniendo las cosas 'en su sitio', sino entender la idea en la tradición cultural que lo hizo realidad". ${ }^{146}$ En general, las obras de todos los historiadores que escribieron sobre la Montaña Blanca no tenían significados contradictorios. Esto se debe, por supuesto, a las fuentes que se pueden utilizar para tratar el tema de la Montaña Blanca, pero también al origen compartido de la orientación nacional y cultural. Se puede deducir de mi texto que el tema de la Montaña Blanca y sus consecuencias fue un tema muy sensible en la historiografía checa y tratado con frecuencia hasta ahora.

El texto muestra cómo llamó más la atención atraer el tema de la batalla de la Montaña Blanca durante la primera parte del siglo XX, la época del nacionalismo y del deseo por el estado propio. Después de la creación de Checoslovaquia continuó este curso de investigación histórica. Igualmente, después de la Segunda Guerra Mundial durante el año 1948 se inclinó la percepción del año 1620 a la idea del progresismo y el humanismo de la nación checa. 1989 significó un cambio en la historiografía del anticomunismo. Pero también este período ha significado una reflexión del tema y una revisión de los términos historiográficos.

No es mi intención representar a los checos como personas encerradas en su mundo, al contrario, se puede ver la influencia entre historiadores checos y extranjeros. En la última parte se exponen algunos ejemplos: los historiadores checos, Antonín Gindely, Bohdan Chudoba y Josef Polišenský significativamente influyeron en la historiografía extranjera. Gindely publicó sus obras no solo en la lengua checa pero también en alemán y vivió en la monarquía de muchas naciones. Su investigación en los archivos de Europa Central, España e Inglaterra, por ejemplo, además

146 PETRÁŇ, Staroměstská exekuce, p. 291. 
de su vista factográfica fue original y excepcional en su período. Chudoba también investigó en España y además publicó en inglés. Basado en mi conversación con el historiador Rubén González Cuerva en Madrid en 2017, fue Chudoba una persona crucial en la historiografía española hasta finales del siglo XX para los investigadores de la Europa Central. Polišenský presentó también fuentes significativas e informaciones factográficas, pero también presentó nuevas percepciones sobre la batalla de la Montaña Blanca. Polišenský se enfocó en las relaciones entre los países y la historia económica. Por eso cooperó con la revista inglesa Past and Present. En su archivo es posible encontrar su correspondencia con E. Hobsbawm, Ch. Hill y su alumno R. J. W. Evans. Entre otras naciones, Polišenský estuvo en contacto y siguió las obras de J. M. Romein, T. Wittman y A. N. Čistozvonov, asunto que abordaré más a fondo en mi tesis doctoral.

En conclusión, me gustaría volver a mi experiencia de la escuela primaria mencionada en la introducción. De hecho, la enseñanza de la profesora no se desvió demasiado de lo que pudimos observar en la mayoría de las obras mencionadas anteriormente. El remordimiento por el fin de la independencia de las tierras checas fue realmente uno de los momentos más repetidos, hasta ahora, en la historiografía.

(Escrito en checo por el autor y traducido al español por Aneta Psotová)

\section{BIBLIOGRAFÍA}

BAĎURA, Bohumil - POLIŠENSKÝ, Josef, "Falešný obraz Bílé hory”, Československý časopis historický 3, Praha: ČSAV, 1955, pp. 674-679.

BENEŠ, Zdeněk, "Bílá hora a české dějiny po čtyřiceti letech" in: František Kavka, Bílá hora a české dějiny [La Montaña Blanca y la historia checa], Praha: Garamond, 2003, pp. 5-16.

BENEŠ, Zdeněk, "Narratio, noesis a čas. Poznámky k jednomu aspektu chápání dějin a historie", Přednášky z 52. běhu Letní školy slovanských studií [Los discursos de la quincuagésima segunda marcha de La Escuela de verano de los estudios eslavos], Praha: Univerzita Karlova, 2009, pp. 132-139.

BENEŠ, Zdeněk, "Raný novověk v českém historiografickém výzkumu" in: Marie Koldinská (ed.), Základní problémy studia raného novověku [Los problemas principales del estudio de la edad moderna], Praha: Lidové noviny, 2013, pp. 27-53.

EVANS, Robert J. W., “A Czech Historian in troubled Times: J. V Polišenský” in: Tomoko Asomura (ed.), Ad honorem Josef Polišenský (1915-2001), Olomouc: Univerzita Palackého, 2007, pp. 93-96.

GINDELY, Antonín, Dějiny českého povstání léta 1618. Díl 1.-4. [Historia de la revuelta bohemia], Praha: Tempský, 1870-1880.

HOJDA, Zdeněk, "Tragic Triangle. The Netherlands, Spain and Bohemia 1617-1621”, Dějiny a současnost 4, Praha: 1993, p. 64.

HROCH, Miroslav - PETRÁŇ, Josef, 17. století - krize feudální společnosti? [El Siglo XVII - ¿la crisis de la sociedad feudal?], Praha: Svoboda, 1976.

HROCH, Miroslav, "Prof. PhDr. Josef Polišenský, DrSc. 16. 12.1915-11. 1. 2001”, Český časopis historický = The Czech Historical Review, 99/2, Praha: AVČR, 2001, pp. 409-412.

HROCH, Miroslav, "Josef Polišenský a tradice studia obecných dějin na univerzitě Karlově", in: Tomoko Asomura (ed.), Ad honorem Josef Polišenský (1915-2001), Olomouc: Univerzita Palackého, 2007, pp. 169-177. 
HROCH, Miroslav, Hledání souvislostí: eseje z komparativních dějin Evropy [La búsqueda de las relaciones: los ensayos de la historia comparativa de Europa], Praha: Slon, 2016.

CHUDOBA, Bohdan, Španělé na Bílé hoře: tři kapitoly z evropských politických dějin [Los Españoles en la Montaña Blanca: tres capítulos de la historia política de Europa], Praha: Vyšehrad, 1945.

CHUDOBA, Bohdan, Jindy a nyní: dějiny českého národa [Antiguamente y hoy: la historia de la nación checa], Praha: Vyšehrad, 1946.

JANÁČ, Jiř̌́ - IRA, Jaroslav, "Komparace, relace, kontextualizace... České světové dějiny a světové dějiny Česka", Dějiny a současnost 41, Praha: Lidové noviny, 2019, pp. 13-15.

JANÁČEK, Josef, “České stavovské povstání 1618-1620. (Otázky a problémy)", Folia Historica Bohemica 8, Praha: ČSAV, 1985, pp. 7-41.

KAVKA, František, Bílá hora a české dějiny [La Montaña Blanca y la historia checa], Praha: SNPL, 1962.

KUČERA, Jan Pavel, 8. 11. 1620 - Bílá hora: o potracení starobylé slávy české [8 de noviembre de 1620 - La Montaña Blanca: sobre la pérdida de la fama checa antigua], Praha: Lidové noviny, 2003.

MAREK, Pavel, "Španělská strana na císařském dvoře? K problematice jednoho pojmu z politických dějin” Český časopis historický = The Czech Historical Review 113/4, Praha: AVČR, 2015, pp.965-988.

PÁNEK, Jaroslav - EVANS, Robert J. W., "České dějiny nabývají smyslu ve středoevropských souvislostech”, Dějiny a současnost 14/2, Praha: Lidové noviny, 1992, pp. 49-51.

PAZDERSKÝ, Roman, "Příběh sporu o smysl českých dějin", Historický obzor I.-II. Praha: Aleš Skřivan ml., 2012, pp. 30-39.

PAZDERSKÝ, Roman, Gollưv styl: studie k historickému myšlení Jaroslava Golla [El estilo de Goll: estudio del pensamiento histórico de Jaroslav Goll], Praha: Editorial Karolinum, 2018.

PEKǍ̌, Josef, Bílá hora: její př́čciny i následky [La Montaña Blanca: sus causas y consecuencias], Praha: Vesmír, 1921.

PETRÁŇ, Josef, "Pozdně feudální lidová hnutî", in: Z českých dějin: sborník prací in memoriam Prof. Dr. Václava Husy [De la historia checa: almanaque de los artículos in memoriam al Prof. Dr. Václav Husa], Praha: Univerzita Karlova, 1966, pp. 107-150.

PETRÁŇ, Josef, "Lid a národ v pobělohorském labyrintu”, in: František Graus (ed.), Naše živá i mrtvá minulost: 8 esejí o českých dějinách [Nuestro vivo y muerto pasado: 8 ensayos sobre la historia checa], Praha: Svoboda, 1968.

PETRÁŇ, Josef, Staroměstská exekuce: několik stránek z dějin povstánífeudálních stavů proti Habsburkům v letech 1618-1620 [Ejecución de la Ciudad Vieja: unos páginas de la historia de la revuelta del estado feudal contra los Habsburgo 1618-1620], Praha: Mladá fronta, 1972.

PETRÁŇ, Josef, "Ke genezi novodobé koncepce českých národních dějin", AUC - Philosophica et historica 5, Praha: Univerzita Karlova, 1982, pp. 67-89.

PETRÁŇ, Josef, "Spor o smysl dějin a dějepisu", Acta Universitatis Carolinae: Philosophica et historica 5, Praha: Univerzita Karlova - Praha 1988, pp. 29-67.

PETRÁŇ, Josef, "Na téma mýtu Bílé hory", in: Traditio et cultus: miscellanea historica Bohemica: Miloslao Vlk, archiepiscopo Pragensi ab eius collegis amicisque ad annum sexagesimum dedicata [Tradición y cultura: Miscelánea historia bohémica: Miloslao Vlk, arzobispo de Praga, por sus colegas y amigos dedicado a los sesenta], Praha: Editorial Karolinum, 1993, pp. 141-162.

PETRÁŇ, Josef, Staroměstská exekuce. Vyd. 4., autorem dopl. a přeprac. [La ejecución de la Ciudad Vieja], Praha: Rodiče, 2004.

POLIŠENSKÝ, Josef, Anglie a Bílá hora [Inglaterra y la Montaña Blanca], Praha: Univerzita Karlova, 1949.

POLIŠENSKÝ, Josef, “Současný stav bádání o Bílé hoře”, Časopis Matice moravské 70, Brno: Matice moravská, 1951, pp. 1-25.

POLIŠENSKÝ, Josef, "Období prosazení a utužení druhého nevolnictví 1620-1627)” in: František Graus (ed.), Přehled československých dějin: these. I, (Do roku 1848) [Resumen de la historia checoslovaca: vol. I (hasta 1848)], Praha: ČSAV, 1954, pp. 407-454.

POLIŠENSKÝ, Josef et al., "Otázky studia obecných dějin I, Prameny k obecným dějinám v českých archivech a knihovnách", Acta Universitatis Carolinae: Historica 4, Praha: Univerzita Karlova, 1957. 
POLIŠENSKÝ, Josef, Nizozemská politika a Bílá hora [La política holandesa y la Montaña Blanca], Praha: ČSAV, 1958.

POLIŠENSKÝ, Josef et al., Documenta Bohemica bellum tricennale illustrantia. Tomus I, Der Krieg und die Gesellschaft in Europa 1618-1648, Praha: Academia, 1971.

POLIŠENSKÝ, Josef, Historik v ménícím se světě [Historiador en el mundo cambiante], Praha: Univerzita Karlova v Praze, 2001.

POLIŠENSKÝ, Josef, Třicetiletá válka a evropské krize 17. století [La Guerra de los Treinta Años y la crisis europea del siglo XVII], Praha: Svoboda, 1970.

PROKEŠ, Jaroslav, "Bílá hora" in: Jaroslav, Prokeš - Miloslav Hýsek (eds.), Doba bělohorská a Albrecht $z$ Valdštejna: sborník osmi statí [Tiempo de la Montaña Blanca y Albrecht von Wallenstein: almanaque de ocho artículos], Praha: Výbor výstavy Albrecht z Valdštejna a doba bělohorská, 1934. pp. 29-60.

RAK, Jiří, Bývali Čechové: české historické mýty a stereotypy [Los checos de pasado. Los mitos históricos y los estereotipo], Jinočany: H\&H, 1994.

RYCHLÍK, Jan, "Bitva na Bílé hoře a mýtus o třistaleté porobě: (transformace mýtu v dějinném vývoji)", in: Literární mystifikace, etnické mýty a jejich úloha při formování národního vědomí: sborník př́spěvků z mezinárodní konference konané ve dnech 20. - 21. 10. 2001 [La mistificación literaria, mitos étnicos y su papel en la formación de la conciencia nacional: almanaque de los artículos de la conferencia internacional de 20 y 21 de octubre de 2001], Uherské Hradiště: Slovácké muzeum v Uherském Hradišti, 2001, pp. 85-93.

WERSTADT, Jaroslav, Odkazy dějin a dějepisců [Herencia de historia y los historiadores], Praha: Historický klub, 1948.

\section{Breve información sobre el autor}

Correo electrónico: martin.kindl@ff.cuni.cz

Mgr. Martin Kindl (*1987), es doctorando del Instituto de Historia Checa de la Universidad Carolina, se ocupa principalmente de la historia del siglo XX y la historiografía checa. Su tesis doctoral se enfoca en las obras del historiador checo Josef Polišenský (1915-2001). 